\title{
LA NEUROÉTICA COMO ÉTICA FUNDAMENTAL
}

\author{
JOSEP CORCÓ \\ Universitat Internacional de Catalunya
}

\begin{abstract}
RESUMEN. En su libro Braintrust, la neurofilósofa Patricia Churchland expone sus ideas sobre lo que la neurociencia ha aportado hasta el momento al estudio de las bases neurológicas del comportamiento ético de los seres humanos. La tesis principal de la aportación de Churchland es que la moralidad se origina en la neurobiología del apego y subraya la relevancia de la oxitocina en el comportamiento cooperativo de los seres humanos, con la pretensión de que la neuroética pueda llegar a constituirse en una ética fundamental. Pero, a mi parecer, ante la propuesta de Churchland se abren interrogantes relevantes, como por ejemplo, ¿por qué debemos comportarnos éticamente? o ¿cuáles son los valores morales? En esta contribución valoraremos las principales ideas de Churchland para intentar mostrar si la neurociencia puede ayudar a contestar estas cuestiones.
\end{abstract}

PALABRAS CLAVE: neuroética, ética fundamental, Churchland, apego, Gould.

\section{Neuroethics as a Fundamental Ethic}

ABSTRACT. In her book Braintrust, the neurophilosopher Patricia Churchland puts forward her ideas about what neuroscience has contributed so far in the study of the neural bases of ethical behaviour in human beings. The main thesis of Churchland's book is that morality has its origins in the neurobiology of attachment and bonding; she stresses the importance of oxytocin in the cooperative behaviour of human beings, and proposes that neuroethics might eventually come to be regarded as a fundamental ethic. In my opinion, however, Churchland's proposal raises some pertinent questions, such as, Why should we behave ethically? or, What are moral values? In this paper we assess Churchland's main ideas in an attempt to show whether neuroscience can be of help in answering these questions.

KEY WORDS: neuroethics, fundamental ethic, Churchland, attachment, Gould.

El término neuroética tiene dos acepciones. La primera se refiere a la ética de la neurociencia: esta acepción haría de la neuroética una rama más de la bioética. Pero la otra acepción es la que nos interesa aquí: la neurociencia de la ética, es decir, los conocimientos que el desarrollo de la neurociencia pueden aportar en la búsqueda de las bases cerebrales del comportamiento ético de los seres humanos.

Alvarez-Díaz distingue entre tres grupos de autores con posiciones distintas respecto a esta segunda acepción de la neuroética: los neuroreduccionistas, los neuroescépticos y los neurocríticos ${ }^{1}$. Como todo esquema se trata de una simplificación, pero para situarnos en el territorio es suficiente como panorama inicial. Los neuroreduccionistas piensan que la neurociencia debe sustituir a la ética porque de alguna manera (con matizaciones en las que no vamos a entrar), la mente humana e incluso el ser humano se identifica con el cerebro. Opuestos a este primer

1 Álvarez-Díaz, J. A., «Neuroética como neurociencia de la ética» en: Revista de Neurología, 57 (8), 2013, p. 377. 
grupo están los neuroescépticos, que mantienen la tesis de que la neurociencia no puede aportar nada especialmente relevante a la ética normativa, ya que el comportamiento ético es una propiedad distintiva del ser humano que no puede fundamentarse científicamente. Finalmente los neurocríticos piensan que la ética no puede ser subsumida por la neurociencia pero tampoco descartan que los avances en neurociencia se tengan que tener en cuenta en el ámbito ético.

El debate, que aquí concretamos en el ámbito de la neuroética, se sitúa en realidad en un terreno mucho más global: ¿puede la ciencia sustituir a la filosofía? Voy a adelantar que mi posición se acerca más al grupo de los neurocríticos: ciencia y filosofía son dos formas de conocimiento humano que tienen objetivos y metodologías distintas, que nos permiten acceder a distintas facetas del mundo real, y que pueden encontrar aspectos de diálogo que les permitan reconocerse como conocimientos complementarios y mutuamente implicados. En el mundo contemporáneo, la ciencia necesita de la filosofía para comprenderse a sí misma, y la filosofía necesita de la ciencia para comprender el mundo.

Como se puede ver el tema es muy amplio. Las propuestas que han despertado más expectación están en el grupo de los neuroreduccionistas. Dentro de este grupo encontramos a Patricia Churchland, una de las más destacadas neurofilósofas de la actualidad. En este trabajo voy a intentar explicar brevemente las principales ideas de Churchland sobre la relación de la neurociencia y la moralidad, con unas consideraciones críticas al respecto.

En primer lugar nos interesa entender lo que Churchland concibe como ética. «La hipótesis predominante», afirma, «es que lo que nosotros, los humanos, llamamos ética o moralidad es una estructura de conducta social en cuatro dimensiones que viene determinada por la interrelación de distintos procesos cerebrales: (1) el cuidado o atención a los demás (...), (2) el reconocimiento de los estados psicológicos de los demás(...), (3) la resolución de problemas en un contexto social y (4) el aprendizaje de prácticas sociales $»^{2}$. Quisiera destacar en este punto la insistencia en la dimensión social de la ética como su única dimensión: no parece que para Churchland la ética pueda tener una dimensión personal o individual, centrada en el interior del ser humano. La ética se concibe como una estructura de conducta social, es decir, de modo externalista. Por lo tanto, la ética se entiende como la base que estructura la conducta social. Churchland lo afirma explícitamente: «La conducta social y la moral parecen ser parte del mismo espectro de acciones $»^{3}$. La diferencia para Churchland estaría en la trascendencia de las acciones morales respecto a las puramente sociales (por ejemplo, no asesinar respecto a hacer un regalo en una boda).

La pregunta que hace Churchland a continuación es muy significativa: «¿De qué modo los cerebros llegaron a preocuparse de los demás? Si mis genes organizan mi cerebro de modo que se centre en mi supervivencia, y en la reproducción y transmisión de esos genes, ¿cómo dichos genes organizan mi cerebro para valorar a los demás? Solamente alcanzamos a comprender una parte de la neurobiología

2 Churchland, P. S., El cerebro moral. Lo que la neurociencia nos cuenta sobre la moralidad, Paidós, Barcelona, 2012, p. 19.

3 Ibid., p. 72. 
implicada en este proceso ${ }^{4}$. En este punto, Churchland se alinea con la corriente más dura de la biología evolutiva, que concibe al ser humano como una estructura que los genes construyen para su propia reproducción. Estamos ante la famosa tesis del gen egoísta de Richard Dawkins. Todos los seres vivos son concebidos por Dawkins como máquinas que los genes construyen con el objetivo de reproducirse ${ }^{5}$. Un objetivo «egoísta» que plantea el gran problema de la justificación del altruismo.

Cogiendo una perspectiva sociobiológica, Churchland basará su propuesta en la estructura neuroquímica de los mamíferos para explicar el comportamiento social humano. Y va a proponer la siguiente tesis: «el apego (...) constituye la plataforma neurológica de la moralidad. En mi uso de la palabra apego estoy adoptando la terminología de la neuroendocrinología, un campo en el que el apego hace referencia a la disposición para cuidar a otras personas, al deseo de estar con ellas y al hecho de entristecerse tras la separación ${ }^{6}$. Es interesante en este punto atender a dos cuestiones. El apego se presenta como la plataforma, es decir, la base biológica de la moralidad. Hay que distinguir, como hace por ejemplo Adela Cortina, entre base y fundamento ${ }^{7}$. No es lo mismo que desde la neurociencia se proponga una base neuronal de la ética, es decir, que sin un cerebro humano no habría comportamiento ético y otra muy distinta es proponer el fundamento de por qué esa conducta es éticamente buena. El apego puede ser una base neuroendocrinológica que es necesaria para la vida social, al menos en el pequeño grupo de los allegados. Pero la neurociencia estrictamente no nos puede decir si el apego es un valor éticamente bueno. Pero además, el apego tiene que ver, como hemos mencionado, con los más allegados, y por lo tanto difícilmente puede constituir la base de toda una moralidad que tiene que alcanzar también a los distantes.

Churchland parece consciente de alguna de las limitaciones de su propia tesis. Por ejemplo, admite que «aunque el apego puede ofrecer una base para la moralidad, no existe un sencillo conjunto de pasos — ninguna operación deductiva ni normas precisas de aplicación- que nos lleve del yo cuido y valoro a la mejor solución para los problemas morales concretos, especialmente los que surgen dentro de culturas complejas» ${ }^{8}$. Este es un ejemplo de la distinción entre base y fundamento. No podemos deducir qué conductas son morales o no en un determinado caso porque la base no aporta valores sino solamente es una base de conducta. Podríamos hacer una hipótesis evolutiva según la cual el apego es bueno para la supervivencia del grupo. Pero entonces cabe preguntarse, como sugiere Adela Cortina, si el fin del ser humano es simplemente sobrevivir o quizás vivir humanamente bien ${ }^{9}$, cuestión que va más allá de la supervivencia del grupo y conduce, entre otros aspectos, a apoyar a los débiles y vulnerables aunque no pertenezcan al grupo propio, sea éste el que sea.

4 Ibíd., p. 23.

5 Dawkins, R., El gen egoísta: las bases biológicas de nuestra conducta, Salvat, Barcelona 1994. Churchland, P.S., o.c., p. 27.

7 Cortina, A., Neuroética y neuropolítica. Sugerencias para la educación moral, Tecnos, Madrid 2014, p. 46.

8 Churchland, P.S., o.c., p. 35.

9 Cortina, A., o.c., p. 139. 
Llegamos con esto a la hipótesis principal de Churchland tal y como ella la mantiene: «La moralidad se origina en la neurobiología del apego y de los vínculos afectivos, depende de la idea de que la red de oxitocina-vasopresina en los mamíferos pueda modificarse para permitir el cuidado a terceros más allá de la propia prole o camada, y que, si se conserva esa misma red como telón de fondo, el aprendizaje y la resolución de problemas se incorporan a la gestión de la propia vida social. Podríamos predecir, por tanto, que la cooperación y confianza son sensibles a los niveles de oxitocina. Esto suscita una cuestión importante: ¿pueden los cambios en los niveles de oxitocina incidir en la conducta cooperativa de los seres humanos?» ${ }^{10}$. Parece que aquí podríamos encontrar un campo abonado para resolver muchos de los problemas humanos, especialmente el cuidado de los más vulnerables, aumentando el nivel de oxitocina de la población.

Pero la cuestión no es tan obvia y presenta claramente sus límites, como admite Churchland: «A pesar de que los datos presentados demuestran que existen relaciones importantes entre la conducta social, la OXT, la VPA y sus receptores, entender la naturaleza precisa de sus relaciones requerirá una mayor comprensión de cómo se toman las decisiones, y del modo en que la percepción afecta y es afectada por las emociones. Además, hay que tener en cuenta que la oxitocina no debería llamarse la molécula de la función social y cognitiva, porque se trata de una parte de una compleja red flexible e interactiva de genes, interacciones entre esos genes, las neuronas, las sustancias neuroquímicas y el entorno, y las interacciones entre el cuerpo y las neuronas ${ }^{11}$. Seguramente faltan también otros factores a tener en cuenta, como la libertad humana, por ejemplo.

Hemos visto un intento de convertir la neuroética en ética fundamental. Pero, a mi parecer, son muchas las objeciones que se pueden realizar para poner en cuestión que preguntas tan relevantes como ¿por qué debemos comportarnos éticamente? o ¿cuáles son los valores morales? puedan ser contestadas por la neurociencia. Siempre se puede decir que todavía la neurociencia no puede contestar a estas preguntas porque su desarrollo es muy inicial. Pero hemos visto como la neurociencia y la ética están en planos distintos. Una manera clásica de subrayar esta diferencia es aludir a la distinción entre el «es» que nos puede describir la neurociencia y el «debería ser» que la ética pretende fundamentar. Este es un tema clásico en el ámbito de la filosofía, pero que también ha sido puesto de relieve por científicos de la talla de Stephen Jay Gould, biólogo evolucionista.

Gould, de manera más general, define el ámbito de la ciencia como el ámbito de los hechos y el de la ética como el ámbito del significado ${ }^{12}$. Son dos ámbitos independientes, y al mismo tiempo es completamente necesario que desde su independencia metodológica dialoguen para conseguir una comprensión cabal del ser humano. Me parece muy acertado el siguiente posicionamiento de Gould: «La ciencia no puede decir nada sobre la moralidad de la moral. Es decir, el descubrimiento potencial por los antropólogos de que el asesinato, el infanticidio, el genocidio y la xenofobia pueden haber caracterizado a muchas sociedades humanas, pueden haber surgido de preferencias en determinadas situaciones sociales, e incluso que

10 Churchland, P.S., o.c., p. 85.

11 Ibíd., p. 95.

12 Gould, S. J., Ciencia versus religión. Un falso conflicto, Crítica, Barcelona, 2000. 
pueden haber sido beneficiosos en determinados contextos, no ofrece en absoluto ningún apoyo para la proposición moral de que debiéramos comportarnos de aquella manera ${ }^{13}$. Sin embargo, aunque la ciencia no pueda decir nada sobre la moralidad de la moral, la neurociencia nos puede aportar interesantes conocimientos que hay que tener en cuenta a la hora de una correcta comprensión del comportamiento moral humano. A su vez, estos conocimientos neurocientíficos necesitan un marco de interpretación ético que sólo la filosofía puede proporcionar.

Universitat Internacional de Catalunya

Josep CORcó jcorco@uic.es

[Artículo aprobado para publicación en diciembre de 2016]

13 Ibid., p. 69. 